\title{
Comparative Study: Role of Handheld Doppler with Complementary Duplex Ultrasonography in Planning of Perforator Flaps for Reduction Mammoplasty
}

\author{
MAMDOUH O. KHALIFA, M.Sc.**; NADER G. EL-MELEGY, M.D.*; GAMAL I. MOSSA, M.D.** and \\ TAREK G. SHOUKR, M.D.* \\ The Departments of Plastic Surgery* and General Surgery**, Faculty of Medicine, Tanta University
}

\begin{abstract}
Background: The aim of reduction mammoplasty is to reposition the NAC with adequate projection by basing the NAC on a reliable pedicle that provides good vascularity, preserves sensory innervation and enables post-operative breastfeeding.

Aim of Study: The purpose of this study is to introduce a breast reduction technique designed to reduce the incidence of post-operative nipple-areola complex ischemia and necrosis following reduction mammoplasty by using handheld doppler in detection of perforators and compare it's finding with complementary color duplex ultrasonography.

Subjects and Methods: The study included 10 patients that underwent reduction mammoplasty. The average body mass index of our patients was 33.4. The average suprasternal notch to nipple distance was $41.3 \mathrm{~cm}$. The average resection weight per side was $1324.6 \mathrm{~g}$.

Results: None of the cases experienced NAC necrosis.

Conclusion: The pedicle constructed with the aid of preoperative perforator identification with a Doppler and compare it's finding with complimentary color duplex ultrasonography is an effective technique for breast reduction that results in a very low rate of post-operative ischemia and necrosis of the nipple-areola complex.
\end{abstract}

Key Words: Handheld Doppler - Perforator flaps - Reduction mammoplasty.

\section{Introduction}

THE aim of reduction mammoplasty is to reposition the NAC with adequate projection by basing the NAC on a reliable pedicle that provides good vascularity, preserves sensory innervation and enables post-operative breastfeeding [1]. The main sources of blood supply to the breast were described

Correspondence to: Dr. Mamdouh O. Khalifa,

The Department of Plastic Surgery, Faculty of Medicine, Tanta University by many authors [2-7], but the variations in the of blood supply to the NAC make the pattern of blood supply unpredictable in each single case. Van Deventer, in an anatomical study, found an asymmetric pattern of blood supply to the breast with variations between the left and the right side of the same cadaver in the form of partial or complete absence of branches to the NAC from the main sources. So, he concluded that it is impossible for a surgeon to predict the blood supply of the breast that is to be operated upon. If this is not taken into consideration, there is a real risk of nipple necrosis in some cases, even in the hands of the most competent and experienced plastic surgeon [8]. To solve this problem, we present a method to be sure that the blood supply to NAC is contained within the designed pedicle during reduction mammoplasty. This is done using the hand-held Doppler and compare it's finding with complementary color duplex ultrasonography to detect the sites of the most powerful arterial perforators supplying the NAC.

\section{Subjects and Methods}

This study (prospective randomized study) was done after approval from Ethical Committee of Research Center of Tanta University and written consent from all patients included in this study. The study was conducted on 10 patients who underwent reduction mammoplasty for breast hypertrophy, in the period from May 2017 to May 2018. All patients were subjected to the following: Full clinical history taking and full clinical examination. The patients, included in this study, should be free from coagulopathies, uncontrolled hypertension, anti platelet and anticoagulant drug administration. All patients signed an informed consent including 
surgery details, medical photography and the potential use of their data in medical publications. Breast anthropometric measures were recorded; suprasternal notch to nipple (SSN-N) distance, infra-Mammary Fold to nipple distance (N-IMF). Investigations; breast ultrasound and mammographic studies and standard pre-operative investigations were done for all patients.

Detection of perforators: Fig. (1) patients will be marked in supine position with handheld probe Doppler ultrasonography. Using a hand-held Doppler, a search is made for the perforators supplying the NAC with the most potent signal. This is done along a line parallel to, and $2 \mathrm{~cm}$ lateral to the
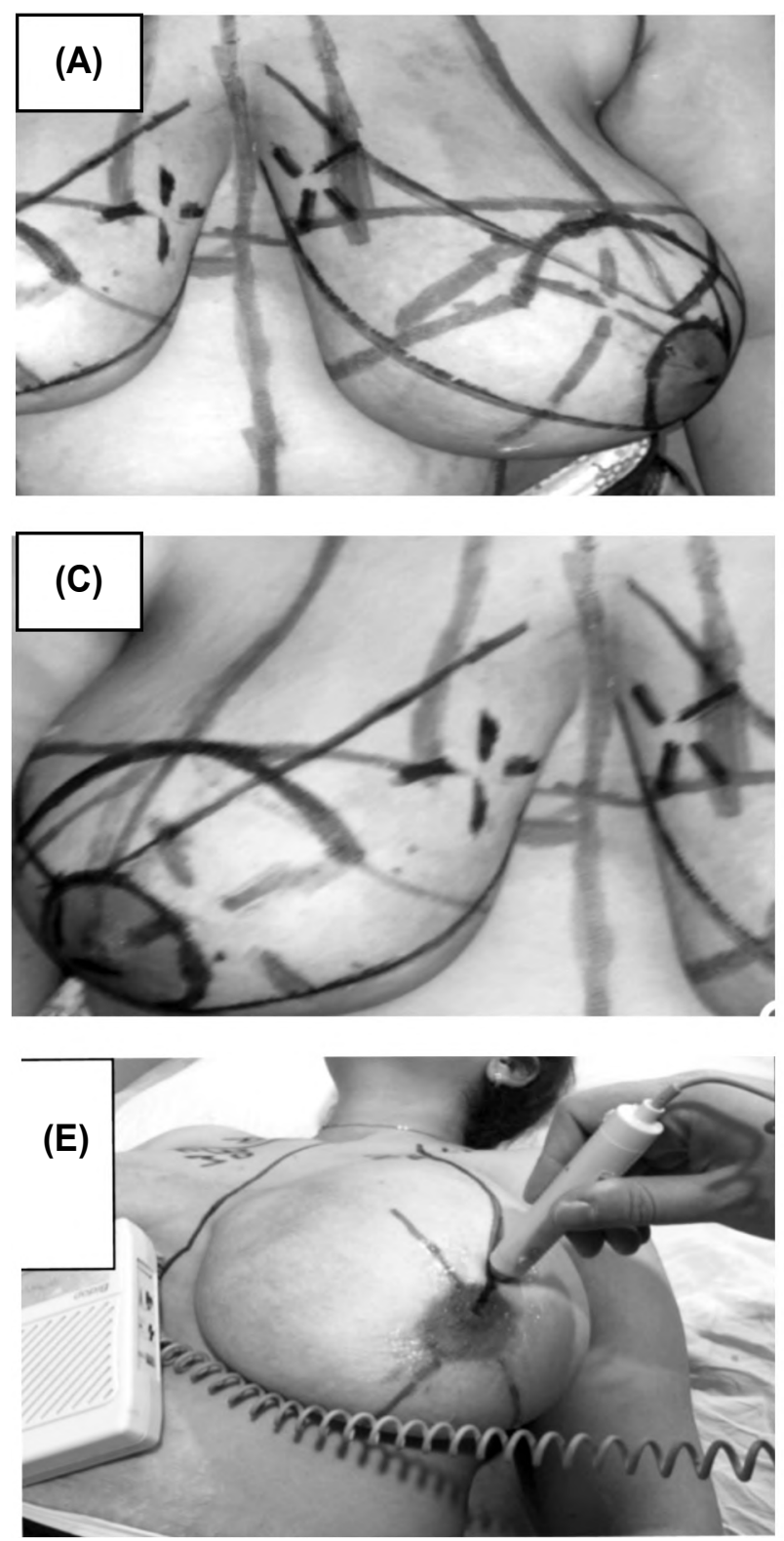

sternal border for Internal Mammary Artery (IMA) perforators and along the anterior axillary line for Lateral Thoracic Artery (LTA) perforators; these are marked at the proximal end of the perforator. Then probe will be placed on the breast around the areola and traveling medially, laterally, caudally and cranially. Vessels traveling most superficial to the skin surface, with the largest diameter and linear axis, will be marked roughly on the skin surface Then a complementary colored duplex ultrasonography will be done to confirm these points (major perforators) Fig. (2). The pedicle is designed to include the detected perforator at its base from internal mammary perforators, LTA and or intercostal perforators.
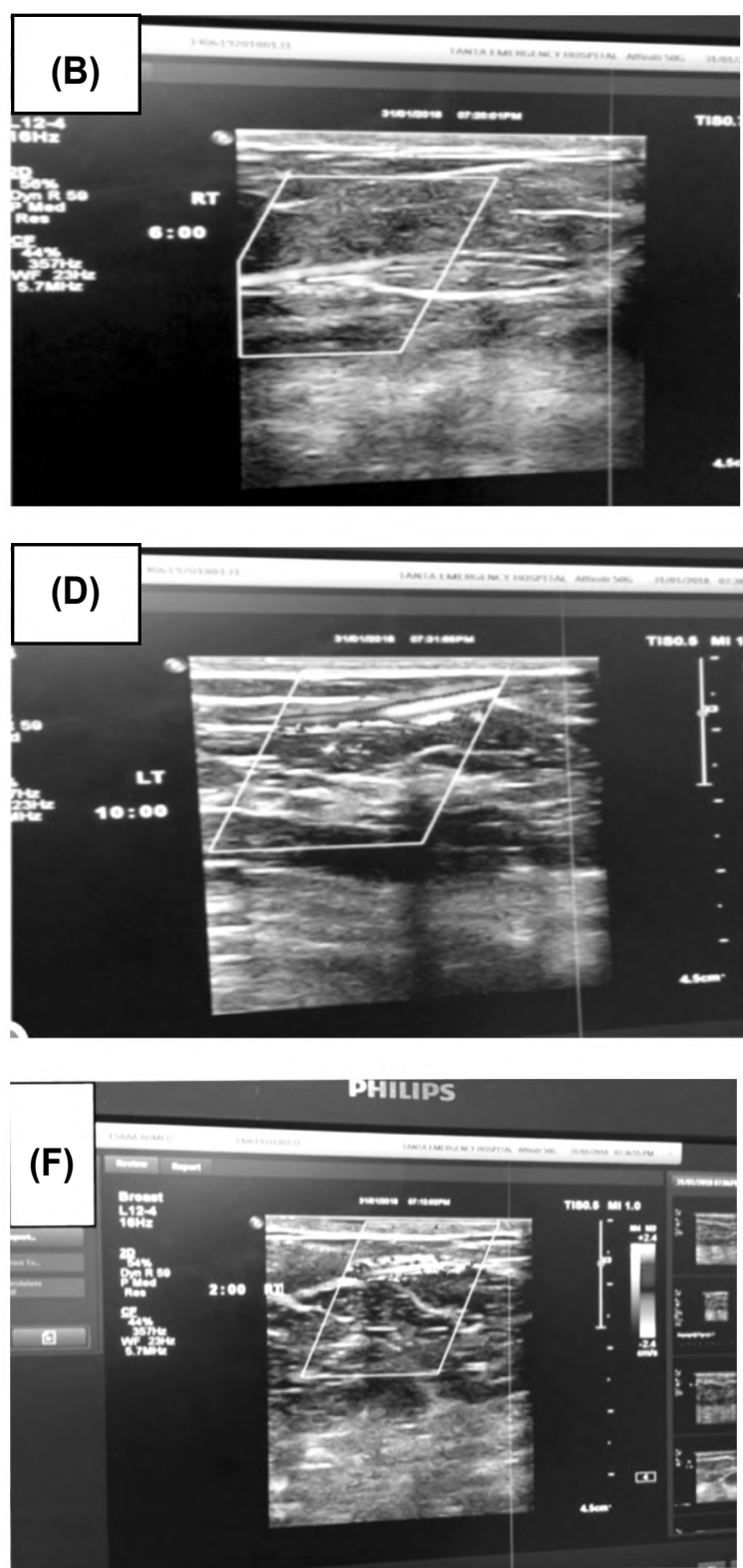

Fig. (1): (A-D) Detection of perforators of IMA by handheld doppler and complementary color duplex ultrasonography, (E-F) detection of perforators of around NAC by handheld doppler and complementary color duplex ultrasonography. 

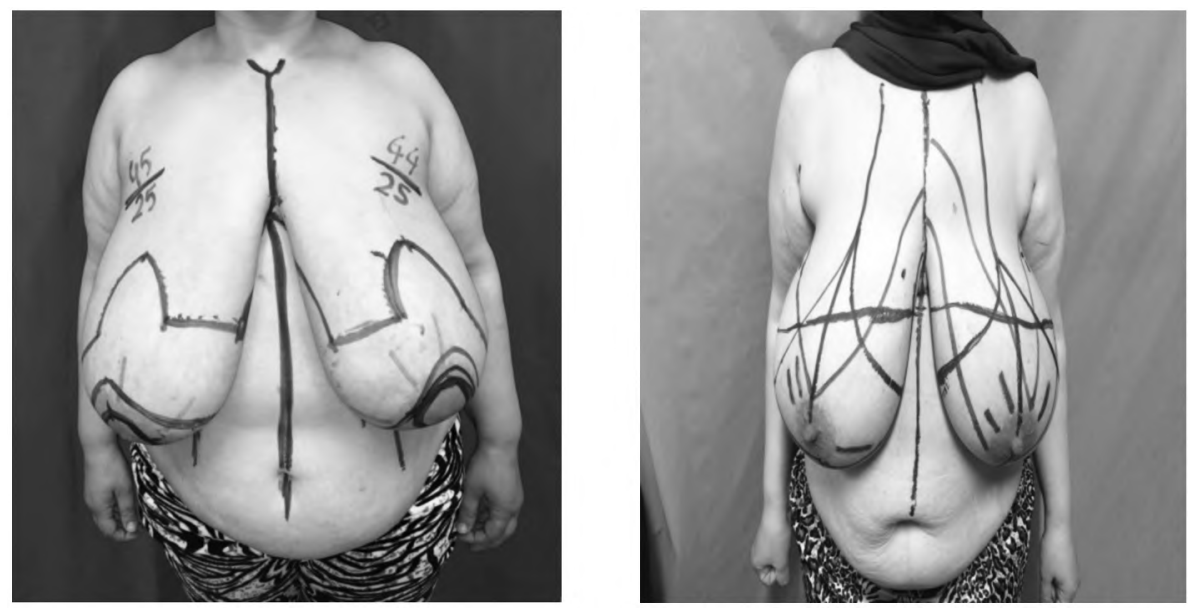

Fig. (2): Pre-operative marking.

Compare doppler finding with complementary color duplex ultrasonography: Color Duplex scanner was used to preoperatively visualize the perforators detected by handheld doppler: Present or absent, site (distance from the lateral sternal border), the diameter.

At first, each patient was positioned in the supine position, and then the intercostal spaces from the ${ }^{2 n-5 t h}$ were marked on both sides of the chest. Regions scanned using B-mode ultrasonography with a linear probe frequency of $12 \mathrm{MHz}$ after adjusting the B-mode gain to clearly visualize the deep fascia, then a color Duplex with pulsed Doppler wave was used to detect the perforators after adjusting the following parameters: Pulse repetition frequency at low setting level to detect low velocities; color gain to avoid over or under estimation of the perforator's diameter; the Doppler angle to be less than 60 degrees; and the sample volume of the Doppler beam.

The site of the detectable perforator(s) was projected by a colored marker on the patient's skin so as to estimate perforation site from the sternum and the inner diameter of each perforator was measured.

Pre-operative marktings: Fig. (2): The patients were marked in the standing position with the midline, breast meridian, original areola marking and Infra-Mammary Fold (IMF). The IMF is transferred to the midline then to the anterior surface of breast, as sometimes the level is different on both sides and in this case the marking is done based on the higher side. The highest point of the new areola is marked at the level of the inframammary fold. The original areola is marked 4$5 \mathrm{~cm}$ in diameter. The vertical lines are drawn by moving the breast supero-laterally and supero- medially and marking them to lie in line with the breast meridian and being $6-8 \mathrm{~cm}$ in length. Then the vertical lines are joined to each other $3-6 \mathrm{~cm}$ above the infra-mammary fold according to breast size. Then, the pedicle is designed to include the detected perforator at its base.

\section{Operative technique:}

Under general anesthesia, de-epithelialization of the pedicle was done. The dermis of the pedicle was divided at the base of pedicle just at the junction of de-epithelialized area with breast skin. Skin flaps were raised with a thickness of 1-2cm stopping their dissection at the 2 nd intercostal space superiorly. Medially, skin flap dissection was stopped $1 \mathrm{~cm}$ lateral to the site of the perforator detected pre-operatively with Doppler to avoid its injury. Laterally skin flap dissection is stopped $1 \mathrm{~cm}$ medial to the site of the Doppler-detected perforator. Then, resection was performed above and below the pedicle as needed to achieve the desired breast size. Resection is done down to the level of the retro-mammary space but taking care to preserve the part of the pedicle in continuity with the preoperatively marked perforators medially and laterally. Breast shaping sutures were inserted between the superior surface of the medial and lateral part of the pedicle at the dermal level using $2 / 0$ absorbable suture from above downward. The last of these sutures is performed using $2 / 0$ non-absorbable suture and fixed to the pectoral fascia at the 2 nd intercostal space to create upper pole fullness. One suction drain was inserted on each side. The vertical and peri-areolar incisions were closed in 2 layers so that the vertical limb is $6-8 \mathrm{~cm}$ in length. A short horizontal limb is added as needed to deal with the dog ear formed at the lower end of the vertical incision. Gauze dressing and adhesive tape were applied. Patients were scheduled for monthly 
follow-up visits during which the healing process, shape of the breast, subjective sensation of the NAC were assessed and recorded by the operating surgeon. A clinical photography session was done after 1 year as well as the recording of a new set of anthropometric measures (as in pre-operative assessment), follow-up period, and complications if any. The weight of the resected tissue was recorded for patients. Complications were documented by photographs once detected.

\section{Results}

This study included 10 patients. Table (1) shows the numbers of perforators detected by handheld doppler, comparison of it's finding with color duplex ultrasonography, average diameter of perforators and average distance of IMA perforators from lateral sternal border.

Table (1): Detection of perforators.

\begin{tabular}{|c|c|c|c|c|}
\hline & $\begin{array}{c}\text { Number } \\
\text { detected } \\
\text { by Doppler }\end{array}$ & $\begin{array}{r}\text { Number } \\
\text { detected } \\
\text { by duplex }\end{array}$ & $\begin{array}{l}\text { Average } \\
\text { diameter } \mathrm{c} \\
/ \mathrm{mm}\end{array}$ & $\begin{array}{c}\text { Average } \\
\text { distance from } \\
\text { sternum } / \mathrm{cm}\end{array}$ \\
\hline $\begin{array}{l}\text { - IMA } \\
\text { perforators }\end{array}$ & 43 & 41 & $1.23 \mathrm{~mm}$ & $1.23 \mathrm{~mm}$ \\
\hline $\begin{array}{l}\text { - LTA } \\
\text { perforators }\end{array}$ & 37 & 35 & $1.09 \mathrm{~mm}$ & \\
\hline $\begin{array}{c}\text { - Intercostal } \\
\text { perforators }\end{array}$ & 32 & 29 & $0.8 \mathrm{~mm}$ & \\
\hline
\end{tabular}

Table (1): Shows the numbers of perforators detected by handheld doppler, comparison of it's finding with color duplex ultrasonography, average diameter of perforators and average distance of IMA perforators from lateral sternal border.

Table (2): Pre-operative data.

\begin{tabular}{ll}
\hline & Patients \\
\hline Age (mean \pm SD) & $35.5 \pm 7.3$ \\
Average BMI & $32.4 \%$ \\
Average resection weight & $1324.6 \mathrm{~g}$ per side \\
SSN-N distance & $31.4 \mathrm{~cm}$ \\
\hline
\end{tabular}

Table (2): Shows average age, BMI, resection weight, SSN-N distance.
The average BMI was $32.4 \%$ and the average resection weight was $1324.6 \mathrm{~g}$ per side (range 700 2070g).

Table (3): Operative data of the patients.

\begin{tabular}{lc}
\hline & Operative data \\
\hline Operative time (minutes) & $168 \pm 27.7$ \\
Excised tissue (grams) & $765 \pm 235.9$ \\
NAC elevation (cm.) & $19.4 \pm 5.4$ \\
NAC viability immediate ately & \\
post-operative: & \\
$\quad$ Good & $19(95 \%)$ \\
Questionable & $1(5 \%)$ \\
\hline
\end{tabular}

Table (3): Shows operative data.

Table (4): Post-operative NAC necrosis and sensation.

\begin{tabular}{lc}
\hline & Patient No \\
\hline NAC necrosis & $0 / 10(0 \%)$ \\
No. of patients with decreased NAC sensation & $0 / 10(0 \%)$ \\
No. of patients with lost NAC sensation & $0 / 10(0 \%)$ \\
\hline
\end{tabular}

Tables $(4,5)$ showed post-operative data are: None of the cases experienced NAC necrosis or fat necrosis, post-operative NAC sensation was preserved in all of cases, minor wound disruption occurred in two cases and all were managed conservatively with repeated dressing with good healing. The mean follow-up period was 26.1 months Figs. $(3,4)$.

Table (5): Post-operative complications.

\begin{tabular}{cc}
\hline & Patient No. (\%) \\
\hline Pseudoptosis & $1(10 \%)$ \\
Asymmetry & $1(10 \%)$ \\
Scar complications: & \\
Hypertrophy & $1(10 \%)$ \\
Pigmentation & $2(20 \%)$ \\
Widening & $1(10 \%)$ \\
Puckering & $1(10 \%)$ \\
Dog ears & $0(0 \%)$
\end{tabular}



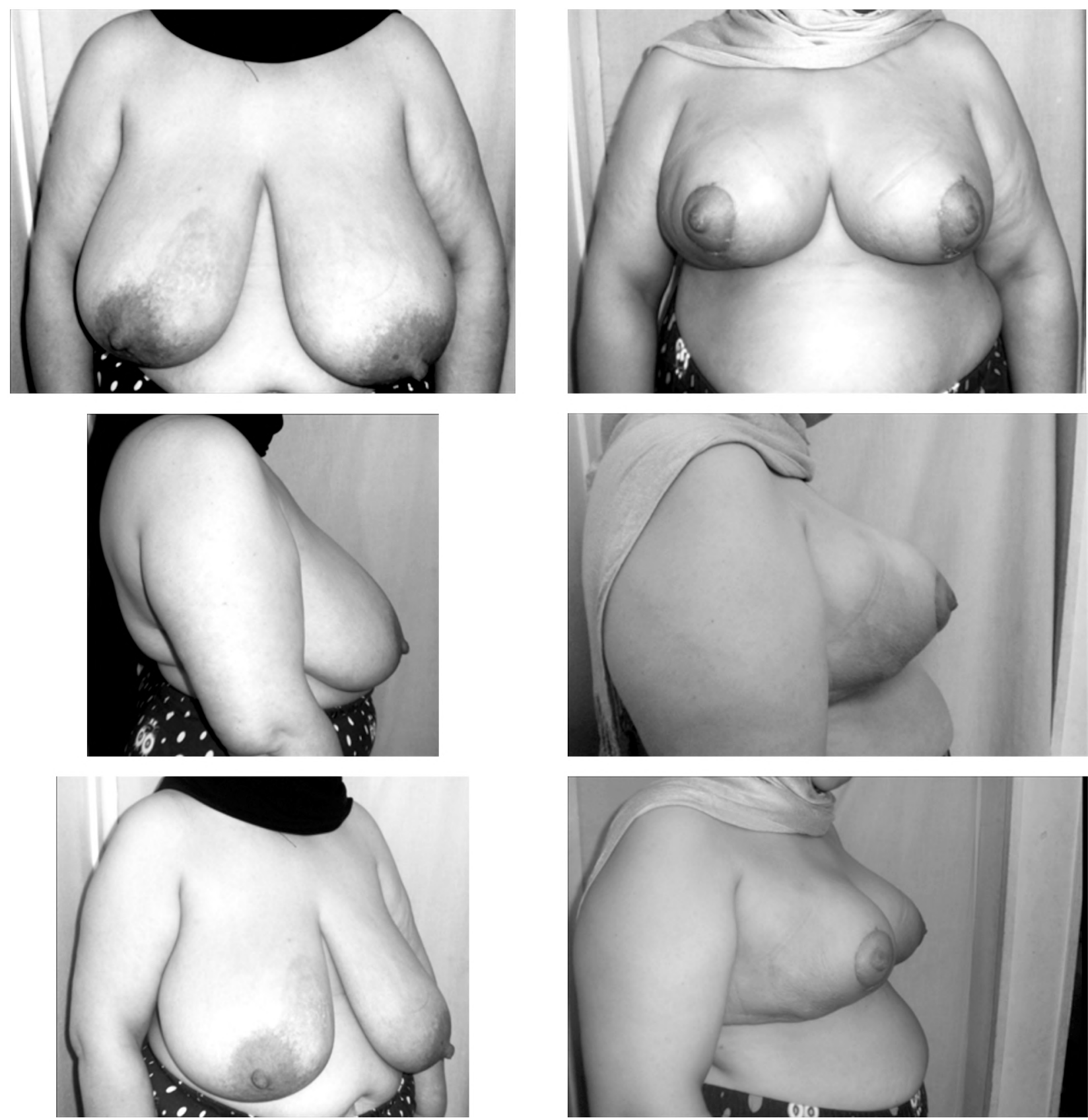

Fig. (3A): Case 1 a 35 years old patient with a SSN-N distance of a $41 \mathrm{~cm}$, resection weight of $1970 \mathrm{~g}$ from each breast, preoperative and early post-operative ant. 

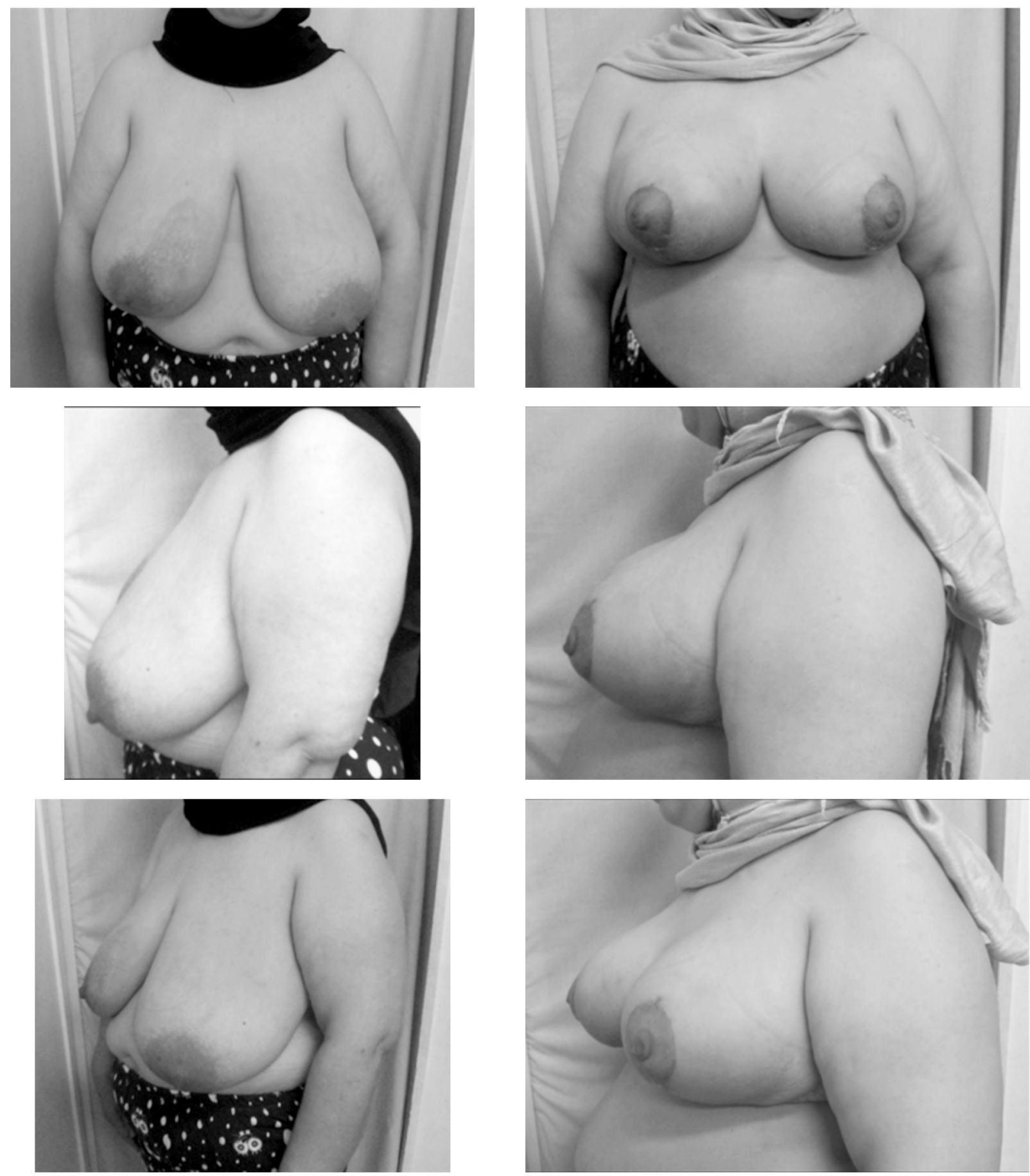

Fig. (3B): Case 1 pre-operative and early post-operative ant post, left oblique, left lateral views. 

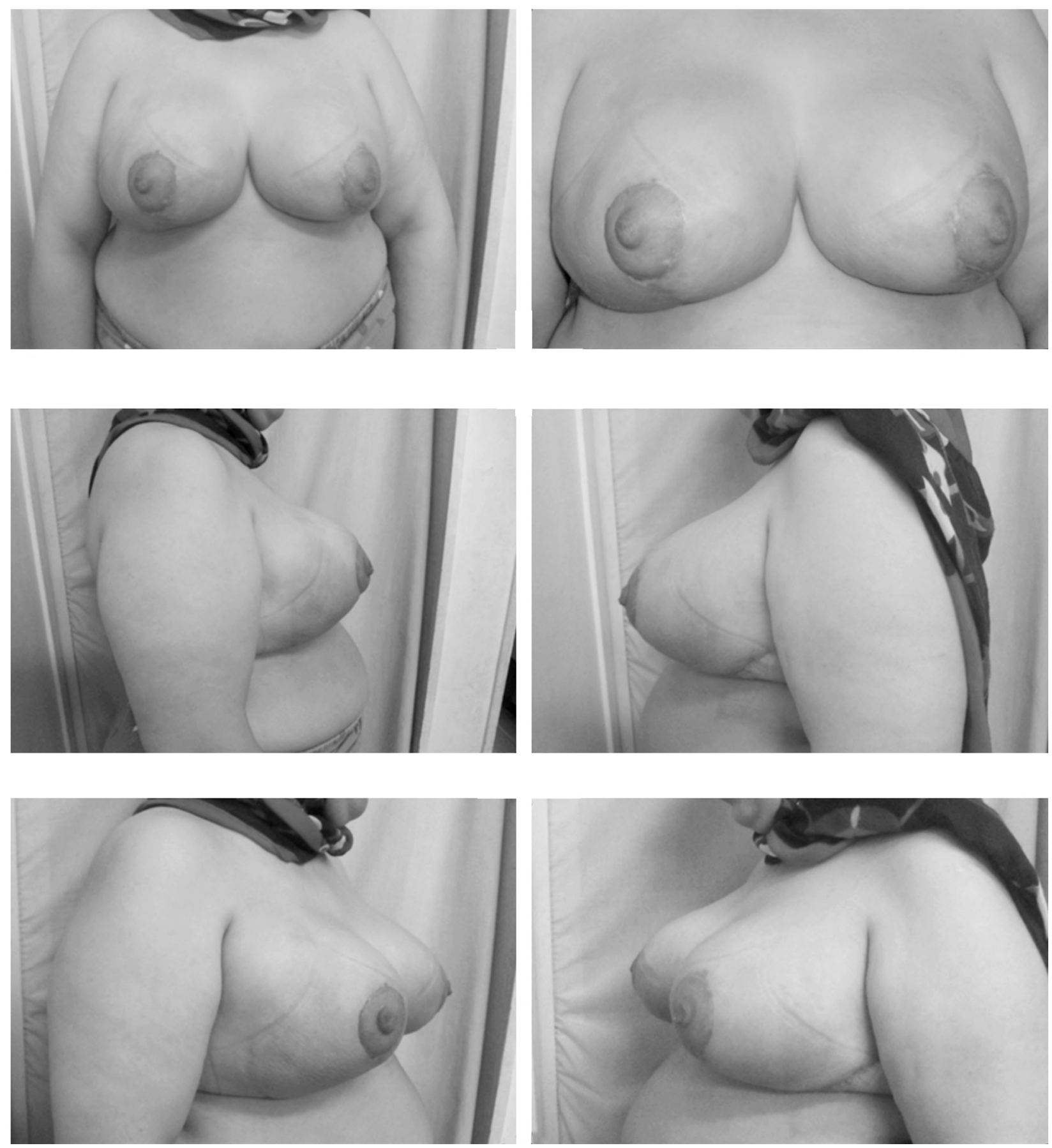

Fig. (3C): Case 1 one year post-operative ant post, oblique, lateral views. 

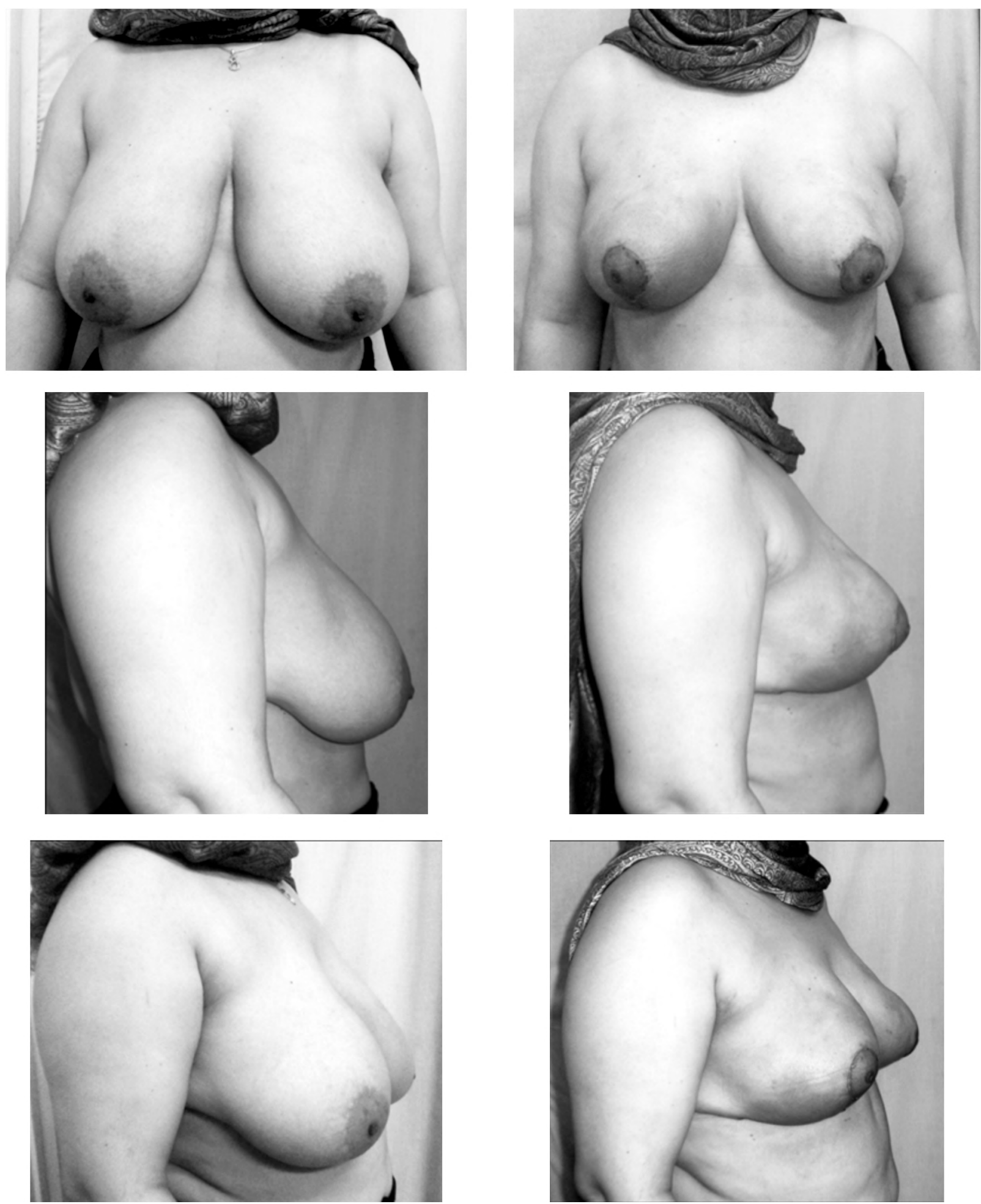

Fig. (4A): Case 2 a 39 years old patient with a SSN-N distance of a $41 \mathrm{~cm}$, resection weight of $1090 \mathrm{~g}$ from each breast, pre-operative and early post-operative ant post, right oblique, right lateral views. 

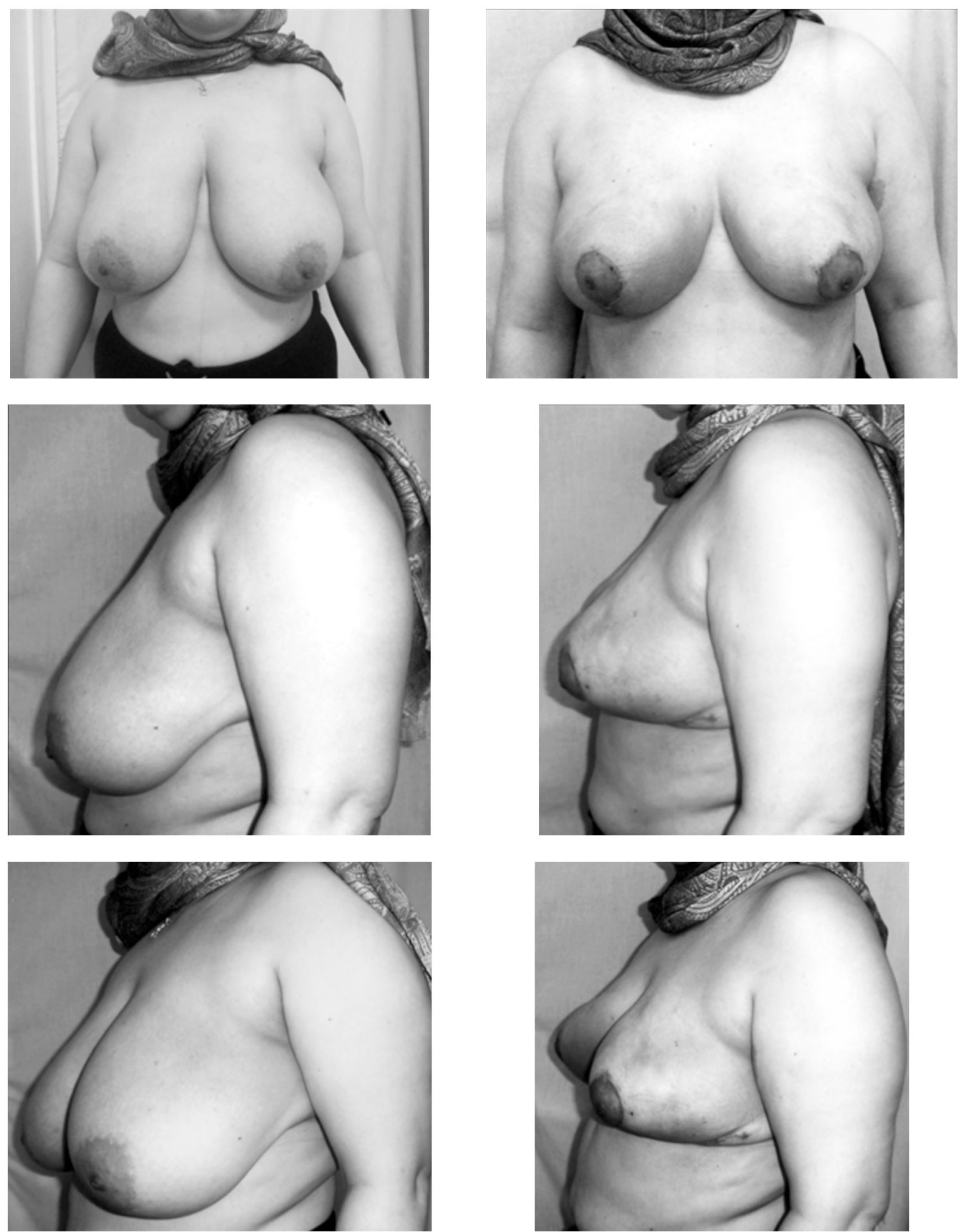

Fig. (4B): Case 2, pre-operative and early post-operative ant post, left oblique, left lateral views. 

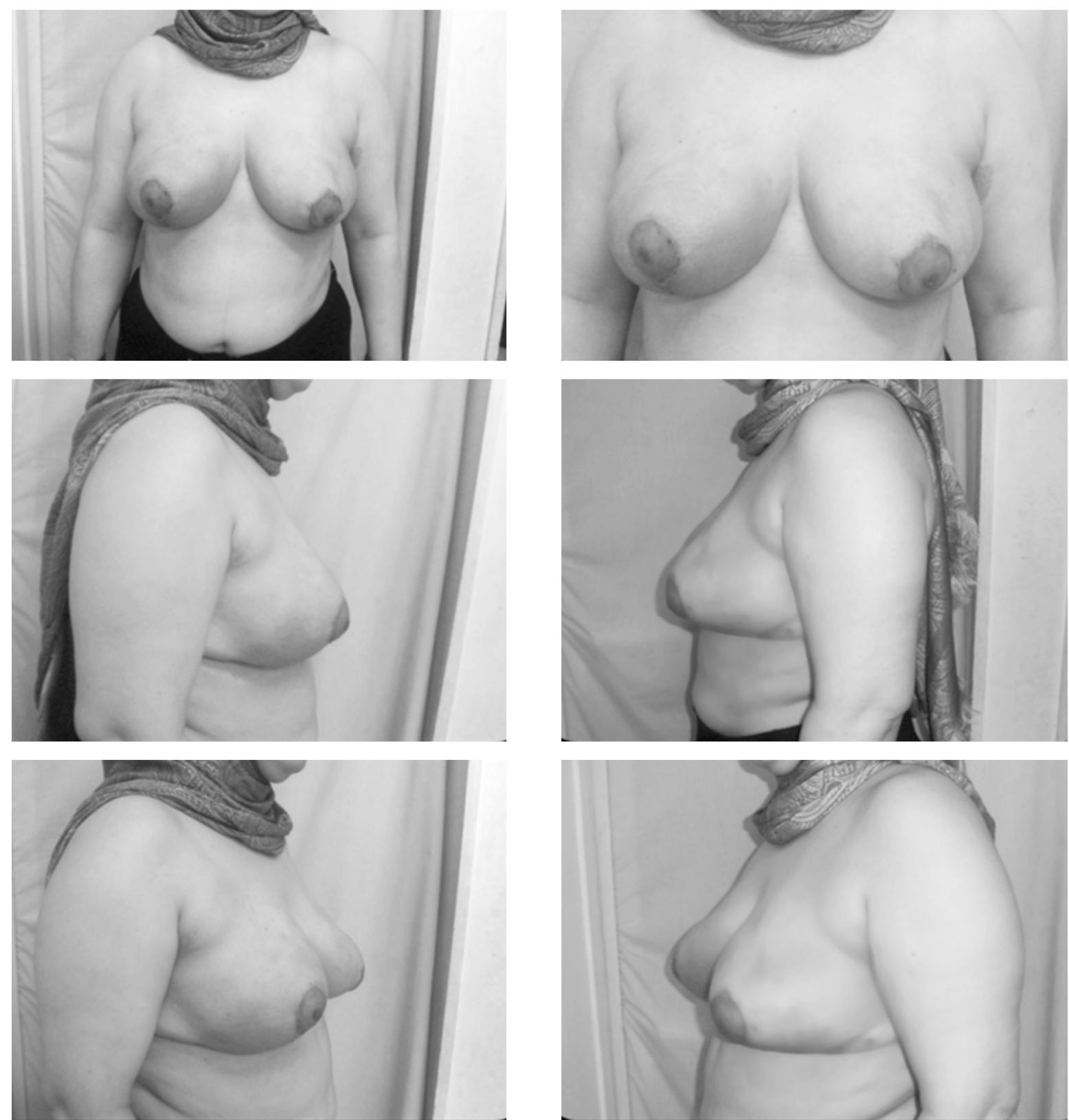

Fig. (4C): Case 2 one year post-operative ant post, oblique, lateral views.

\section{Discussion}

Over the last few decades, breast reduction techniques became numerous. However, there is no reduction mammoplasty technique that is suitable in all situations; every technique has its advantages and advocates as well as its disadvantages and opponents. Due to the fact that NAC necrosis and loss of NAC sensation are the most terrifying complications of reduction mammoplasty, in outcomes related to a particular technique, safety is mainly dependent on assuring blood and nerve supply to the NAC. Three main arterial routes supply the breast; the internal mammary artery, the lateral thoracic artery, and the intercostal arteries $[10,11]$. Internal mammary artery perforators are the most reliable and constant source of blood supply to the breast [5].

Often, the perforating branches from the internal thoracic artery course relatively parallel to each other in a lateral direction. They run tortuously either above or below the nipple toward the branches from the lateral thoracic artery. Branches from the lateral thoracic artery usually run roughly parallel to each other, on variable segmental levels, medially either above or below the nipple toward the perforating branches of the internal thoracic 
artery, to anastomose with these arteries. This is the most abundant between the anastomoses of different arteries supplying the NAC suggesting a segmental pattern of blood supply [8]

Van Deventer, in an anatomical study, found an asymmetric pattern of blood supply to the breast with variations between the left and the right side of the same cadaver in the form of partial or complete absence of branches to the NAC from the main sources. So, he concluded that it is impossible for a surgeon to predict the blood supply of the breast that is to be operated upon [8]. The incidence of NAC necrosis was reported to be $6 \%$ in superior pedicle reduction mammoplasty [12] and $1.28 \%$ in superolateral pedicle reduction mammoplasty [13] Eighty-four percent of our patients had resection weights of over $1000 \mathrm{~g}$. Those patients fall in the category of gigantomastia with a high rate of postoperative complications (including NAC necrosis) that makes some surgeons prefer a free nipple graft as a choice for this kind of patients [14]. Many authors tried to minimize NAC necrosis by preoperatively detecting the course of the arteries supplying the NAC and including them in their pedicles [21]. Hall-Findlay documented 126 breasts in 63 patients with a predictable pattern of internal mammary artery perforators with at least two of them included in a true superomedial pedicle [15] Horta et al., reported the use of pre-operative Doppler ultrasound to detect perforators in 22 cases of reduction mammoplasty.

They reported successful results with average resection weights of $820 \mathrm{~g}$ per breast and no cases of NAC necrosis [16]. Basaran et al., described the use of custom-made pedicles, based on predetermined vessels by Doppler ultra-sound, in 16 gigantomastic reduction mammoplasty patients. Their average resection weight was $1795 \mathrm{~g}$ per breast, and they did not encounter any case of NAC necrosis [17]. Based on the anatomical facts reported by Van Deventer, there may be an absence of one or more of the branches of the internal mammary or lateral thoracic artery and the remaining branches constitute the dominant blood supply to NAC [8] The use of pre-operative pencil Doppler to detect the sites of emergence of theses dominant vessels with the strongest signal ensures that they are included in the pedicle used during the procedure. The mere reliance on maintaining the medial and lateral pedicle attachments to the chest wall does not guarantee the safety of the pedicle used as one or both of these random attachments may not contain a blood supply to the NAC. Therefore, none of the cases of our patients experienced partial or total NAC necrosis. In an anatomical study, the blood supply of supero-medial pedicle came from the $1 \mathrm{st}$ and 4 th internal mammary artery perforators with absence of the 2 nd and 3 rd. In this case, a classic medial pedicle without use of Doppler in marking will not be vascularized. In addition, in the same cadaver, the other breast was vascularized with the ${ }^{3 r d}$ perforator of the internal mammary artery with the 1 st, 2 nd and 4 th perforators absent [8].

This is a clear example that demonstrates the basis of our technique and the significant value of pre-operative detection of perforators. We think that the use of pre-operative Doppler detection of perforators with complementary color duplex ultrasonography proves especially effective in breast reductions with medial or lateral pedicles as their blood supply is not so widely distributed as that of the inferior pedicle that is served by multiple sources. Internal mammary artery perforators (mainly 2 nd and ${ }^{3 \mathrm{rd})}$ supplying the superomedial pedicle run at a distance of 10.3 and $4.2 \mathrm{~mm}$ from the skin surface at the areola boundary and at $3 \mathrm{~cm}$ from the areola, respectively. The accompanying veins run at 2.6 and $3 \mathrm{~mm} \mathrm{[4].}$

So, the incisions made at the base of the pedicle at the dermal level do not interrupt the perforators that run in the pedicle and at the same time, allow for maximum mobility, shaping and rotation and/or advancement of the pedicle. The venous drainage of the breast is composed of superficial and deep systems. The deep system includes the perforating branches of the internal mammary and posterior intercostal veins and tributaries of the axillary vein. The superficial system runs just deep to the superficial layer of the superficial fascia and includes transverse veins (91\%), running medially to end in internal mammary vein perforators, and longitudinal veins (9\%) running superiorly to empty in superficial veins of the lower neck [9] .

Accordingly, the pedicle used in all our cases includes most of the transverse veins that constitute most of superficial venous drainage of the NAC. The nipple areola complex is innervated by the $3 \mathrm{rd}$ to ${ }^{\text {th }}$ intercostal nerves. This occurs through their lateral branches of their internal cutaneous branches and through the superficial and deep branches of their lateral cutaneous branches [18]. Hamdi et al., described the latero-central glandular pedicle technique for breast reduction and he found superior preservation of NAC sensation which he explained by maintaining the full thickness of breast tissue laterally down to the pectoral fascia. This maximizes the chance of preservation of sensation as the anterior branch of the lateral branch of the 4 th 
intercostal nerve, that is the main sensory nerve to NAC, can run superficial or deep $[19,20]$. In the technique we report here, the lateral part of the breast is preserved in full thickness around the Doppler-detected perforator. This ensures that this important nerve is included in the pedicle. This explains the preservation of NAC sensation (Kind: Touch tactile sensation) post-operative shown in this study when compared with the pre-operative sensation.

The technique described in this study is based on pre-operative detection of the sites of perforators and then tailoring the pre-operative markings and the operative dissection pattern accordingly to include them in the designed pedicle. This technique maximizes the preservation of NAC vascularity and sensation independent of the resection weight as we are guided by known locations of vessels. In addition, as demonstrated in this study, it proved safe and effective in patients with resection weights more than $1000 \mathrm{~g}$ per side.

\section{Conclusion:}

We concluded that handheld doppler with complementary color duplex ultrasonography is an accurate modality to assess the perforators. The technique described uses a simple low-cost tool, i.e., the hand-held Doppler with complementary color duplex ultrasonography to avoid the most devastating complication in reduction mammoplasty which is NAC necrosis. At the same time innervation to the NAC is preserved with satisfactory breast shape and size.

\section{Acknowledgements:}

This research was carried out without funding.

\section{Conflicts of interest:}

No conflicts of interest declared.

\section{Authors contributions:}

All authors had equal role in design, work, statistical analysis and manuscript writing. All authors have approved the final article work.

\section{References}

1- YAZICI I., DEMIR U., FARIZ S., et al.: Meridian pediclebased breast shaping in reduction mammaplasty: A technical modification. Aesthetic Plast. Surg J., 37 (2): 3729, 2013.

2- DM O'DEY, PRESCHER A. and PALLUA N.: Vascular reliability of nipple-areola complex-bearing pedicles: An anatomical microdissection study. Plast. Reconstr. Surg., 119: 1167-77, 2007.

3- NAKAJIMA H., IMANISHI N. and AISO S.: Arterial anatomy of the nipple-areola complex. Plast. Reconstr. Surg., 96: 843-5, 1995.
4- MICHELLE Le ROUX C., KIIL B.J., PAN W.R., et al.: Preserving the neurovascular supply in the Hall-Findlay superomedial pedicle breast reduction: An anatomical study. J. Plast. Reconstr. Aesthet. Surg., 63: 655-62, 2009.

5- PALMER J.H. and TAYLOR G.I.: The vascular territories of the anterior chest wall. Br. J. Plast. Surg., 39: 287-99, 1986.

6- LOUKAS M., DU PLESSIS M., OWENS D.G., et al.: The lateral thoracic artery revisited. Surg. Radiol. Anat., 36: 543-9, 2014.

7- REID C.D. and TAYLOR G.I.: The vascular territory of the acromiothoracic axis. Br. J. Plast. Surg., 37: 194-212, 1984.

8- VAN DEVENTER P.V.: The blood supply of the breast revisited. Plast. Reconstr. Surg., 137: 1388-97, 2016.

9- FOURNIER P.F.: Ch.17: Strombeck breast reduction technique. In: Shiffman MA, Di Guiseppe A (eds) Body contouring: Art, science and clinical practice. Springer, Berlin, pp. 155-67, 2010.

10- HAMDI M., WURINGER E., SCHLENZ I., et al.: Anatomy of the breast: A clinical application. In: Hamdi M, Hammond DC, Nahai F (eds) Vertical scar mammoplasty. Springer, Berlin, pp. 1-8, 2005.

11- VAN DEVENTER P.V.: The blood supply to the nippleareola complex of the human mammary gland. Aesthetic Plast. Surg., 28: 393-8, 2004.

12- SETALA L., PAPP A., JOUKAINEN S., et al.: Obesity and complications in breast reduction surgery: Are restrictions justified? J. Plast. Reconstr. Aesthet. Surg., 62: 1959, 2007.

13- CÁRDENAS-CAMARENA L.: Reduction mammoplasty with superolateral dermoglandular pedicle: Details of 15 years of experience. Ann. Plast. Surg., 63: 255-61, 2009.

14- HAMMOND D.C., O'CONNOR E.A. and KNOLL G.M.: The short-scar periareolar inferior pedicle reduction technique in severe mam-mary hypertrophy. Plast. Reconstr. Surg., 135: 34-40, 2015.

15- HALL-FINDLAY E.J.: Discussion: The blood supply of the breast revisited. Plast. Reconstr. Surg., 137: 1398400,2016

16- HORTA R., SILVA P., FILIPE R., et al.: Use of Doppler in breast reduction with superomedial or superolateral pedicles. Aesthetic Plast. Surg., 34: 680-1, 2010.

17- BASARAN K., UCAR A., GUVEN E., et al.: Ultrasonographically determined pedicled breast reduction in severe gigantomastia. Plast. Reconstr. Surg., 128: 252e-259e, 2011.

18- SARHADI N.S., DUNN J.S., LEET F.D., et al.: An anatomical study of the nerve supply of the breast, including the nipple and areola. Br. J. Plast. Surg., 49: 156-64, 1996.

19- BLONDEEL P.N., HMADI M., VAN De SIJPE K.A., et al.: The latero-central glandular pedicle technique for breast reduction. Br. J. Plast. Surg., 56: 348-59, 2003.

20- HAMDI M., BLONDEEL P., VAN De SIJPE K.A., et al.: Evaluation of nipple-areola complex sensitivity after the 
latero-central glandular pedicle technique in breast reduction. Br. J. Plast. Surg., 56: 360-4, 2003.

21- ELMELEGY N.G., SADAKA M.S., HEGAZY A.M. and
ABDELDAIM D.E.: Treatment of Gigantomastia Using a Medial-Lateral Bipedicle Reduction Mammoplasty: The Role of Doppler-Assisted Pre-operative Perforator Identification. Aesthetic Plast. Surg., 42 (1): 73-9, 2018.

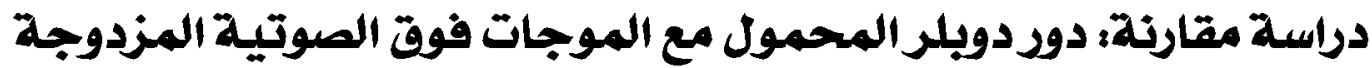

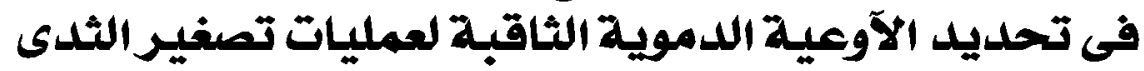

تهدف عملية تصغير الثدى إلى إعادة وضع الحلمة والهالة على بعد مناسب عن طريق إسناد الحلمة والهالة على سديلة مناسبة ويحافظ على الإحساس ويمكن من الرضاعة الطبيعية بعد العملية الجراحية.

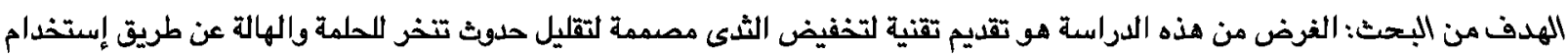

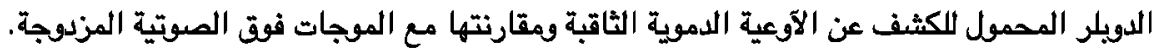

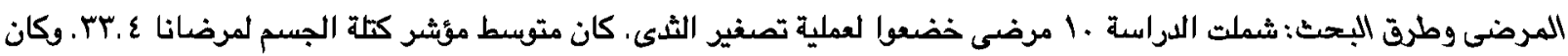

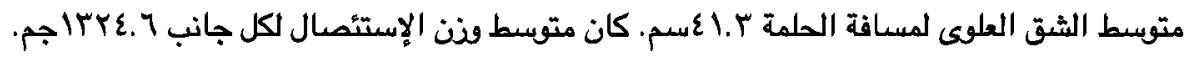

$$
\text { النتائج: لم تشهه آى من الحالات تخر للحلمة آو الهالة. }
$$

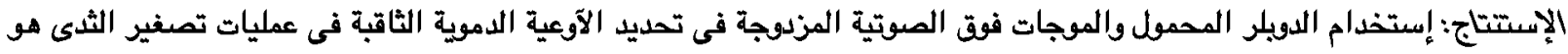
طريقة فعالة وغير مكلفة فى تجنب المضاعفات الناتجة من العملية مثل تنخر الحلمة والهالة. 